\title{
The Nature and Relation of the Three Proofs of God's Existence in Descartes' Meditations
}

\section{David N. Stamos York University}

My aim in this paper is to examine the nature of and the relation between Descartes' three proofs of God's existence in the Meditations. Within this aim I want to pursue and argue three interrelated theses: (I) that Descartes' three proofs of God's existence in the Meditations are in fact (or rather function as, were intended by Descartes as) deductive demonstrations, (II) that all three proofs are logically independent of each other, and (III) that the ordering of the three proofs in the Meditations was for psychological rather than logical or methodological reasons.

After one has read Descartes' Meditations for the very first time, it will probably come as a surprise to learn that there are basically two ways of regarding the nature of the three arguments for God's existence in the Meditations. The prima facie way is, of course, to view them as deductive inferences, as arm-chair proofs. In this way if you assent to the truth of the premises and if you agree that the form of the argument is valid, then you must (logical must) assent to the truth of the conclusion. The other way, interestingly, is to view the arguments in question not as inferences at all but rather as meditative exercises leading in the end to the intuition that God necessarily exists. If a label is required for this second way, we may call these arguments introspective ostensive proofs. Unlike demonstrative proofs, ${ }^{1}$ of which classical examples

1 There is considerable scholarly dif ficulty occasioned by Descartes' ambiguous use in his corpus of the Latin and French equivalents of the words "deduction" and "demonstration." Concerning "deduction," Descartes, on the one hand, in the Rules for the Direction of the Mind. defines this term as meaning "the inference of something as following necessarily from some other propositions which are known with certainty" (I:15). On the other hand, in Part Three of the 
may be drawn from geometry, these proofs prove by "pointing" or "showing." For instance, if I want to prove to you that snow exists, the decisive way is not to produce some sort of a priori inference but rather to take you to a place where there is snow. This, indeed, is the typical way we prove things in everyday life. But now as regards the three proofs of God's existence in the Meditations, on this view the "showing" or "pointing" is not in an external sense as with the snow example, but rather in an internal, introspective sense, the intended result being, as already said, the gaining of a private intuition that God necessarily exists.

Perhaps the most detailed defense of this second view of the proofs in the Meditations was given by Stanley Tweyman (1979). In his view both proofs in the Third Meditation are "paedagogic devices and not demonstrations, and should be appreciated as such" (p. 177). (He also includes the third proof in this category, the

Principles of Philosophy, on the topic of explanatory hypotheses for physical phenomena, Descartes says "And if it is thought that the hypothesis is false. I shall think I have achieved something suf ficiently worthwhile if everything deduced from it agrees with our observations: ... “ (I:255). From these and other examples Desmond Clarke (1977) in his extensive survey concludes that for Descartes 'the word 'deduction' covers a wide range of inferential procedures, such as induction [which for Descartes includes any inference which involves a series of deductive steps], ar guments by analogy, deductive inference in fornal disciplines such as logic or mathematics, hypothetico-deductive explanations, retrodeductive inferences, or any ar gument the structure and evidentiary value of which is clear" (p. 115). As for the term "denonstration" Clarke concludes that "The result of a 'deduction' is what Descartes calls a demonstration, although the word 'demonstrate' is also used in contexts where it simply means 'to show clearly' (for example, by providing unambiguous observational evidence)" (p. 1 15). However, as we shall see in the context of Descartes' analysis-synthesis distinction. Descartes also uses the term "demonstration" to denote an inferential process rather than just its product. Given the above ambiguity and the purposes of the present work, then, when I use the term "deductive demonstration" (or synonymously "demonstrative proof") I mean it in the narrow (contra Descartes) though thoroughly modern sense of deductive inference (not necessarily syllogistic, and not necessarily involving Descartes' restriction quoted in the Rules above). My main purpose is to distinguish and contrast it to a very dif ferent kind of demonstration, what I have terned "introspective ostension." Whereas both the former and the latter involve the practical matter of psychological success or failure, only the deductive kind of demonstration involves the logical matter of soundness or validity. 
ontological proof in the Fifth Meditation, as we shall see a little later on.) Tweyman goes on to say that "it is clear that the proofs of God's existence in the Third Meditation should not be assessed in terms of validity and soundness: they are to be assessed solely in terms of whether or not they are able to turn the attention to the connection between the self and God" (p. 179). "Once the mind," he continues a little further, "has been unprejudiced and the need for establishing the connection between the idea of God and the idea of self has been recognized, it only remains to have the required intuition of this connection in order to know that God exists" (p. 179). 2

To this interpretation of Descartes' program (and I must stress here that it is an interpretation) Tweyman suggests that he can find Descartes' own concurrence not inside but outside the Meditations in his related writings. "The most important passage in this connection," Tweyman tells us, "is to be found in the Replies to the second set of Objections" (p. 177). Tweyman brings to our attention Descartes' discussion therein (II:110-111) ${ }^{3}$ in which Descartes draws a distinction between the analytic and synthetic styles of proof. Tweyman tells us that according to Descartes only the latter style employs demonstrations but that he (Descartes) used

2 For a similar though not quite as extreme view , see Hatfield (1986). According to Hatfield. "Descartes' Meditations are not so much a continuous ar gument as a set of instructions for uncovering the truths that lie immanent in the intellect.

Not that there are no arguments in the Meditations: the language of argument is interspersed throughout the work. But some conclusions seem to arrive out of nowhere, without discursive ar gument-such as the conclusion that the essence of matter is extension, or that one can discover in one' $s$ thought the idea of an infinite, benevolent being" (pp. 47-48). Hatfield, however . seems quite undecided and even ambiguous on, and certainly does not attempt to answer , the question whether the three proofs of God's existence in the Meditations are introspective ostensions or deductive inferences. (That they could be both is a possibility I will examine later on.) At one point he says "the immediate apprehension of the idea of God serves as a basis for the ar gument to God's existence (Third and Fifth Meditations)" (p. 50). Elsewhere, however . he says "the cognitive exercises of the Meditations are engineered ... to exercise one's intuition through the illumination of the cogito and the proofs of God's existence, ... “ (p. 71).

3 The numbers in Roman numerals refer to the particular volume of the Cottingham ef al. $(1985,1991)$ translation of Descartes' philosophical works. The numbers following the colon refer to pages in those volumes. 
the former style in the Meditations. The former style is appropriate for metaphysics, the latter for geometry. As to why, Tweyman tells us:

In geometry, the primary notions are readily accepted, given that they accord with what the senses reveal; hence in geometry what remains is to demonstrate what follows necessarily from the primary notions with which we begin. But in metaphysics, the senses prejudice the mind so that its primary notions are not perceived clearly and distinctly. In metaphysics, therefore, the problem is to direct the attention toward its primary notions so that they can be apprehended clearly and distinctly. In the Fifth Meditation Descartes makes the same point, namely, that were it not for prejudice, a knowledge of God would be intuitive: ... [p. 178]

Now clearly, to simply point out in contradiction to this view and in support of the former deductive view that Descartes often calls his arguments for God's existence "proofs" (e.g. II:10:45:166, III:231:376, etc.) just won't do; for clearly “proofs" can be basically of two sorts, either inferential or ostensive. Therefore nothing is gained by such a response. A more detailed analysis is required. 4

But it seems to me that one does not have to spend much effort to dismantle the second view as expounded by Tweyman, and that this can be accomplished by a few relatively simple moves.

First, Tweyman, it seems to me, gives us not an altogether accurate picture of Descartes' distinction between the analytic and synthetic styles of proof. Indeed on at least one point I think it can be shown that he is incorrect, and that this has serious negative repercussions for his view. According to Tweyman, the synthetic style "suits geometry, but not metaphysics" (p. 177). Now, although it is true that Descartes does say something like this (cf. II:111), to

4 For a modest and brief attempt at combining these two views into one and attributing this to Descartes, see, for instance, Copleston (1963:123). 
infer from this as Tweyman obviously does that for Descartes the analytic style (the style of the three proofs in the Meditations) is not geometric is just plain mistaken. In his Second Set of Replies Descartes considers the proposal that he should set out his arguments in a "geometrical fashion" so as to make his proofs easier to perceive "at a single glance" (II:110). And to this he replies, in effect, that he has already set them out in a geometrical fashion (cf. II:9). He says "I make a distinction between two things which are involved in the geometrical manner of writing, namely, the order, and the method of demonstration." As for the order, what is involved is that whatever comes first must not depend on whatever comes later, and whatever comes later must depend on whatever came before. This order, he tells us, "I did try to follow ... very carefully in my Meditations." As for the method of demonstration, he tells us that "this divides into two varieties: the first proceeds by analysis and the second by synthesis." The analytic style employs the actual steps in which the proof in question was "discovered methodically," with the result that the attentive and sympathetic reader will feel that he is discovering the proof for himself. The synthetic style, on the other hand, does not reproduce the order of methodological discovery, and so does not inspire in the reader a sense of discovery; rather it merely sets the proof out in compact and dry form, demonstrating the conclusion from a combination of "definitions, postulates, axioms, theorems and problems" (II:111).

The important point in all of this is that according to Descartes both the analytic and synthetic are styles of demonstration and both are geometric. (He even attributes both styles to ancient geometers (II:111; cf. II:4-6).) We may therefore infer that the difference between the two styles of demonstration or proof is not anywhere near so radical as Tweyman would have us believe, viz. a difference between introspective ostension on the one hand and deductive inference on the other. Rather both the analytic and synthetic styles are of the nature of the latter, namely deductive inference; in both styles the conclusion deductively follows (in principle) from the premises. This is why Descartes labeled both styles geometric. That he obliged his objector and recasted his three proofs in the synthetic style was not, as Tweyman thinks, to illustrate how unsuitable the synthetic style is for metaphysics; after all, Descartes clearly thinks 
he has succeeded in recasting his arguments from the one style to the other. No, Descartes' purpose was rather to illustrate what he himself says is the principal difference between the two styles. This difference is not a matter of logic; it is not that the one is inferential and the other not. Descartes thinks them both geometrical. Rather the difference is primarily didactic; the synthetic style is best for compelling the assent of "argumentative or stubborn" readers (II:111), whereas the analytic style, since it reproduces the methodological order of discovery, is best as a "method of instruction" (II:111), as a method best suited for engaging the attention of the readers and from which the willing and attentive readers will derive the most benefit (II:112). There is benefit, then, to be derived from both styles. But indeed Descartes goes even further. He tells us that "both" styles are "necessary" if we are to derive what he calls the "full benefit from my work" (II:113). For this purpose he therefore proceeded with a short exposition of his Meditations in the synthetic style.

There is a further implication from all of this that I will reserve for section III. But for present purposes it will be sufficient to note that, far from supporting his thesis, Tweyman's principal piece of evidence, upon closer inspection, actually supports the contrary thesis, that Descartes' three proofs in the Meditations (or rather at this point the first proof) are of the nature of deductive inferences.

This interpretation is I think borne out if we turn to the Meditations and look at the proofs themselves. But first we must establish that they indeed involve premises separate from a conclusion. Unfortunately this is only made explicit outside the Meditations. But in both of the passages I am about to examine the reference in each is assuredly to the Meditations, as an examination of their respective contexts makes clear.

The most important premise in the Third Meditation is, quite simply, the statement that there is in Descartes' mind an idea of God. As for the dependence of the first two proofs on this idea, Descartes states quite clearly in his First Set of Replies: “... that there is within me the idea of a supremely perfect being. The whole force of my proof [Descartes here refers to the first two proofs jointly] depends on this one fact" (II:78). Note, then, that his proof does not establish this fact; rather it depends on it. Note also that 
he calls this fact a fact and not a hypothesis. We may further observe that the interpretation that the statement of this fact serves as a premise in Descartes' proofs is clinched in his letter to Mersenne dated July, 1641. Descartes clearly states that "the one ["the idea we have of God'] can serve as a means or premiss to prove the other ['the proposition 'God exists"]" (III:186).

Keeping this in mind, when we go back to the Third Meditation we will, I think, find strong evidence to support the above interpretation. Looking at Descartes' first proof, we find established prior to his conclusion that God exists the fact that he has within him an idea of God. But it is not just a simple idea of God; rather it is a composite idea and it is arrived at purely by intuition without any deduction. Specifically, it is the idea of a "supreme God, eternal, infinite, immutable, omniscient, omnipotent and the creator of all things that exist apart from him" (II:28). Clearly, then, the statement of this introspectively observable fact must serve as a required premise if we are to regard Descartes' first proof as a deductive inference. And this is precisely what we find. For as we continue in the Third Meditation we find this premise combined with a number of other premises which we may list as follows:

1) every effect must have a cause (this is implicitly presupposed throughout the argument; cf. II:80).

2) "there must be at least as much reality in the efficient and total cause as in the effect of that cause" (II:28; cf. II:97).

3) the objective reality in an idea must have been derived "from some cause which contains at least as much formal reality as there is objective reality in the idea" (II:28-29).

4) "there cannot be an infinite regress here" (II:29).

5) I am finite and not wholly perfect (II:31).

From the combination of these five premises with the previous premise which states as a fact the idea Descartes has in him of God, Descartes restates this idea and then following in the same 
paragraph summarily states that "from what has been said it must be concluded that God necessarily exists" (II:31; italics mine). That God really exists, then, is not here a further intuition, as Tweyman would have us believe, but in fact a demonstrative conclusion separate from the intuitions and premises from which it is derived. Descartes here quite apparently thought that these five premises along with the antecedent premise containing his composite idea of God were jointly sufficient to validly conclude that God exists. Indeed his "must" in the passage quoted above is evidently a logical must. That he quite apparently thought his conclusion valid and the argument sound because he claims all of the five premises are intuitively clear by the natural light and therefore cannot be doubted (II:27-31) is no argument against this interpretation. 5 It only raises

5 Interestingly, it is this fact and others like it-principally Descartes' blatant Scholastic presumptions in his proofs of God' $s$ existence, in apparent disregard of his earlier hyperbolic doubt, and moreover in spite of his privately expressed scorn for Scholastic philosophy (cf. III:161) - that has led a number of scholars to posit what they call "dissimulation hypotheses," hypotheses that state that Descartes intentionally misrepresented major portions of his philosophy: for instance, that in putting forward his proofs of the existence of God, especially in the Third Meditation. Descartes was intentionally insincere and dishonest, that those proofs do not represent his true view, and that he had ulterior motives of a practical kind, prompted mainly by the condemnation of Galileo in 1633. (See, for instance, Loeb 1986.) While I sympathize somewhat with the strengths of this view, my own slant on the matter is a bit dif ferent. It seems to me that Descartes not only (of course) wanted to avoid the type of sacred condemnation that was leveled against Galileo, but that principally he wanted (i) to supplant Scholastic/ Aristotelian science with his own science, and even more basically and widely (ii) to supplant Scholastic/Aristotelian philosophy altogether and make his own philosophy (metaphysics and science-see his tree in the Principles (I:186)) the official philosophy of the Catholic religion. Intimations of this can be found at least three years before the condemnation of Galileo, specifically in his letter to Mersenne dated April 15, 1630 (III:22-23). But it comes out much more clearly in his later writings. In, for instance, his letter to Hyperaspistes dated August, 1641. he says in regard to the authority of "Aristotle and his followers" that "I do not hide the fact that I trust him less than I trust reason" (III:195). And in his letter to Mersenne dated December, 1640, in regard to his Meditations which he was about to complete, he states that "those who have not yet learnt scholastic philosophy will find it much easier to learn from this book than from their teachers, since they will learn to scom it at the same time" (III:161). Moreover we must also consider his purpose for writing his extensive Principles of Philosophy. Shortly after he had resolved to begin that project, he tells Mersenne in his letter dated 
the question, which Tweyman would not have us raise, about the validity and soundness of the argument. 6

Having established, I think, the deductive and inferential nature of the first proof in the Third Meditation, it is but a little step to conclude the same in regard to the second proof, the proof that follows immediately after it. These two proofs are so closely connected that Descartes himself thought it a matter of little consequence whether the second proof is regarded as a separate proof or as an extension of the first proof (cf. III:231-232). Indeed the second proof involves four of the five premises I listed earlier as necessarily involved in the first proof. (Missing is what I listed as the third premise.) In addition to these four premises we find a number of other premises not found in the first proof, the most perspicuous being that preservation is in reality constant creation (II:33). ${ }^{7}$ As with the other four premises, the only justification of

mid-January, 1641, that his purpose is to present his philosophy "in an order which will make it easy to teach" (III:167), that is, as a university textbook. Indeed his anti-Scholastic sentiments emerge daringly enough even in his published writings. I have in mind not only Part One of his Discourse but especially his Preface to the French edition of the Principles, in which he states "that among those who have studied whatever has been called philosophy up till now , those who have learnt the least are the most capable of learning true philosophy" (I:183)-"true philosophy": that is to say , his philosophy. In this light his Dedicatory letter to the Sorbonne, which prefaces the Meditations, is apparently quite disingenuous. His appeal to "the Dean and Doctors of the sacred Faculty of Theology at Paris." whom in regards to "human philosophy" he calls "second to none," his expressed hope of gaining their of ficial endorsement of his philosophy . was not for the purpose of as he would have them (and us) believe, defeating and even winning over atheists and skeptics (that was but a smoke screen), but to supplant the very philosophy embedded in their university and religious institutions. And all of this was not of course without an element of personal glory (cf. his Discourse Part One (I:115)). Not surprisingly the plan ultimately failed, experiencing massive rejection not only in his own lifetime, but culminating thirteen years after his death in the of ficial condemnation of his philosophy by Rome. (See Jolley 1992.). 6 For an interesting refutation of Descartes' first proof assuming the truth of Descartes' Scholastic assumptions, see Mackie (1982:37-39).

7 A further premise would seem to be the idea that no faculty or power can be in me without my being aware of it (II:34). That every effect resembles its cause (cf. Conversation with Burman (III:339-340) is attributed by Gueroult (1984:186) as yet a further premise, but this is clearly a mistake. for the implicit use of this principle (II:35) and the purpose for which it is used comes after Descartes has concluded his second proof. 
these premises seems to be that they are intuitively clear by the natural light and therefore cannot be doubted. As regards the preservation/creation premise, for instance, Descartes tells us that its intuitive clarity obtains once we fully consider "the nature of time” (II:33). Interestingly, in his Discourse, Part Five (I:133), Descartes tells us that his formulation of this premise was theologically inspired. In fact the inspiration was probably Augustine and Aquinas.8

The point is that the second proof is as inferential and deductive in nature as the first. In fact in broad outline it may be characterized as a process of elimination, concluding the real existence of God as the only possible cause of the existence of Descartes'self. The argument therefore presupposes as a premise the same premise upon which the first proof is based, namely the statement of the composite and explicit idea of God that Descartes has in him. As Descartes himself noted (III:232), without this idea of God in him he could not conclude that God is the cause of his existence. The statement that Descartes has this idea of God, then, serves as a required premise from which, combined with the other premises mentioned, the existence of God is deductively inferred by a process of elimination.

At this point it might be appropriate to notice that according to Descartes this antecedent idea he has in him of God he later concludes in the Third Meditation to be innate (II:35), having always been in him. That it is innate, however, does not mean that all of us can also perceive it in ourselves as he does. Indeed in his letter to Hyperaspistes dated August, 1641, Descartes makes a distinction between an implicit and explicit idea of God; the implicit idea is in all of us, though not many have an explicit idea. Indeed one of the purposes of his Meditations is to make the idea of God in the reader as explicit as possible if it is not already. And yet Descartes is skeptical that he will have much success. "Some people," he says, "will perhaps not notice it even after reading my Meditations a thousand times" (III:194; cf. III:248:336, II:171:348).

Now, just as the first two proofs required first the establishment of the fact that I have in me an idea of God, the exact same is the 
case, I suggest, with Descartes' third proof, the ontological proof in the Fifth Meditation. Clearly, without the aforementioned fact first being established, as with the other two proofs, that there is in me the idea of God, and moreover without that idea being made a little more explicit, the ontological proof cannot be generated.

We can see this even more clearly when we attend to what Descartes means by "God." According to Descartes the idea of God is not a simple idea but rather (just like triangle) a composite of ideas; it is the idea of all of God's many perfections (II:45-47; cf. II:28:31:32). This composite, moreover, is tied together by a further idea, that all of the perfections are inseparable (II.34). This further idea, Descartes claims, is but another of God's perfections. And this is not something he formally proves; rather it is something he introspects.

Descartes' ontological argument, then, is based primarily on one of these perfections in his idea of God, namely, that existence is necessarily one of God's perfections (II:46-47; cf. II:108). Without the attribution of this perfection to God, Descartes clearly could not generate the ontological argument.

But at this point we may wonder, as we did with the first two proofs, whether the nature of this proof is that of a deductive inference or what I have called an introspective ostension. As mentioned earlier, Tweyman (p. 178) thinks that Descartes' third proof is also of the latter variety. Once again he suggests that the conclusion of the proof is yet a further intuition. In support of his interpretation he quotes a passage directly from the Fifth Meditation:

... as regards God, if I were not overwhelmed by preconceived opinions, and if the images of things perceived by the senses did not besiege my thought on every side, I would certainly acknowledge him sooner and more easily than anything else. For what is more self-evident than the fact that the supreme being exists, or that God, to whose essence alone existence belongs, exists? [II:47]

To this admittedly highly suggestive passage Tweyman appends the following footnote: 
This comment of Descartes' in the Fifth Meditation indicates that the proof of God's existence offered there is also not a demonstration, in the technical sense of that term: the removal of prejudice requires the analytic method, and the problem of prejudice is as much Descartes' concern in the Fifth as in the Third Meditation. [p. 178]

In response to this we may begin with the fact that in both his First and Second Set of Replies (II:83 and II:106-107) Descartes recasts his ontological proof from the Fifth Meditation into the form of a syllogism, complete with a major premise, a minor premise, and a conclusion. Clearly Descartes' intention is that of a "demonstration in the technical sense of that term" (to quote what Tweyman says the proof in the Fifth Meditation is not).

But this is not conclusive evidence. Indeed I will suggest that in the Fifth Meditation itself the ontological proof is used ambiguously as both an intuition (per Tweyman) and a deduction (contra Tweyman). How this is so becomes apparent the more we attend to the third proof itself and to the logical geography (to use Ryle's apt term) of certain of its key words.

As regards that proof being a deduction, there are places where Descartes' language seems quite clear and unambiguous. He says, for instance, that "from the fact that I cannot think of God except as existing, it follows that existence is inseparable from God, and hence that he really exists" (II:46). First, notice that from a particular psychological fact Descartes deduces that existence is one of God's perfections; it is therefore not an original intuition. From this deduction he proceeds to make a further deduction, that God actually exists. Next, notice that not only the form but also the language of the argument indicates a deduction, namely his use of the phrases "it follows that" and "and hence that," phrases that don't seem at all appropriate for describing intuitions. Indeed when only a little later he restates his proof, instead of the former phrase "and hence that" he now uses "in inferring that" (II:47).

In addition to this, notice the close analogy Descartes repeatedly draws between his ontological proof of God's existence and proofs in mathematics and geometry. The adding of further properties to 
one's immediate idea of triangle, for instance, he calls "inference" (II:47). And indeed further along on the same page he acknowledges that the further properties inferred may be in no way apparent as the properties began with but may nevertheless be believed as strongly. Moreover, earlier in the Fifth Meditation, before he has begun his ontological argument, Descartes notes that both the basic idea of God and the basic ideas of numbers and shapes are raw data, from which further properties that belong to their nature can be proved. "Certainly," he says, "the idea of God, or a supremely perfect being, is one which I find within me just as surely as the idea of any shape or number. And my understanding that it belongs to his nature that he always exists is no less clear and distinct than is the case when I prove of any shape or number that some property belongs to its nature" (II:45).

On the other hand, as regards the ontological proof being an intuition, we may note not only the important passage quoted by Tweyman, but another (less important) passage as well. Near the end of the Fifth Meditation, Descartes uses the word "perceived" (II:48) in his summary statement that God really exists. While the word "perceived," of course, can be used in reference to the conclusion of a deductive inference, it is also quite appropriate in reference to a direct and single intuition, for example that "everyone can mentally intuit that he exists, that he is thinking, that a triangle is bounded by just three lines, and a sphere by a single surface, ... Perceptions such as these are more numerous than most people realize" (I:14).

Thus the ambiguity. And I suggest that the ambiguity is real, that it is really there in the text. I shall suggest even further that the ambiguity is no accident but expresses a particular design on Descartes' part, a design he foreshadowed in an earlier work.

In his Rules for the Direction of the Mind Descartes takes great pains to distinguish what he means by intuition and deduction, on his view the only two modes of knowing (I:14-15). It is an interesting feature of his thought that he regards the latter (deduction) at some point coalescing with the former (intuition). In Rule Eleven he sums up his thoughts regarding his distinction between the two modes. Intuition, he tells us, is a clear and distinct perception that takes places "all at once, and not bit by bit" (I:37). 
Deduction, on the other hand, "does not seem to take place all at once: inferring one thing from another involves a kind of movement of our mind" (I:37). However, if we go through the deduction over and over again in our mind, providing that the deductive process is not too long it is possible that that process and the intuition that accompanies each step may "coalesce into a single operation" (I:38). In this case "I seem to be intuiting the whole thing at once" (I:38).

The relevance of this to our discussion of the proof in the Fifth Meditation should be obvious. It would appear that Descartes, could we ask him, would tell us that his ontological proof in the Fifth Meditation is both a deduction and an intuition. Since that proof (unlike the proofs in the Third Meditation) involves so few premises and steps, like the Cogito, ergo sum, though an inference (cf. II:100),, 9 it may be grasped all at once and so may properly be called an intuition. 10

But now notice. From Descartes' discussion in the Rules, it would seem that we may therefore infer that for Descartes there are basically two categories of intuitions. The first category is intuitions proper, those ideas clearly and distinctly perceived which involve no deductions whatsoever. The second category of intuitions, on the other hand, does involve deductions; indeed it originates from them.

Now, to which category does the ontological argument in the Fifth Meditation belong? Clearly, it belongs to the second category of intuitions. Tweyman, therefore, has a legitimate point in characterizing that argument as a further intuition. Where he goes wrong, however, is in overlooking that it is the type of intuition that arises from a deductive process. It is therefore, contra Tweyman, quite legitimate to question Descartes' ontological argument in terms of validity and soundness.

In sum, then, as we have seen, all three proofs of God's existence in the Meditations are based on one idea, the idea (or some part of the idea) of God that Descartes finds in his mind. If

9 Cf. Frankfurt (1966:337-338) regarding this point concerning the Cogito.

10 This analysis, I suggest, would also go far in resolving the dispute between Hintikka $(1962,1963)$ and Frankfurt $(1966)$ on whether Descartes' Cogito is an inference or an intuition. Both of these philosophers seem to have overlooked this crucial analysis. 
this idea is left implicit and not made explicit, or if this idea is not even in him (or anyone else) implicitly, then clearly neither the first nor the third proof can ever get started, and indeed all three proofs could never conclude the existence of God.

We may now ask how this antecedent fact which the common premise states is established. But we have already seen the answer. Clearly it is not established as the conclusion from a proof in a formal sense; rather its truth is proved according to Descartes in an ostensive sense, in this case an introspective ostensive sense, as an intuition (cf. I:14-15 and II:35)-hence the mental exercises Descartes puts the reader through antecedent to his first proof. The object of these exercises is to clear away the confusion produced by habit and previous ideas and teachings and by the senses so as to produce a clear introspective vision (cf. II:111-112). This vision, of course, is not according to Descartes God himself, or the conclusion that God really exists, but only the idea of God in us (cf. II:97). Having accomplished a clear introspection of that idea, Descartes then proceeds to use it in three proofs as a premise in conjunction with other premises clearly and distinctly perceived so as to soundly infer (ostensibly) the objective existence of God.

Having, I think, established that all three proofs of God's existence in the Meditations are indeed deductive demonstrations, it remains to be shown that all three proofs are logically independent of each other.

We may begin with the uncontroversial matter of the independence of the first proof in the Third Meditation, the proof based on the idea of God as an effect. No one, to my knowledge, has ever questioned the independence of this proof from the other two, and for obvious reasons. It is the first proof Descartes gives in his Meditations and he elsewhere calls it his main proof. However, it is interesting to note that there are surprisingly few passages in all of Descartes' corpus in which he clearly and explicitly and quite uncontroversially affirms that his first proof in the Meditations is his main proof. This fact (if true) is rather remarkable. In his Synopsis prefacing his Meditations Descartes explicitly calls his 
first proof in the Third Meditation his "principal argument for proving the existence of God" (II:10). No statement could be more explicit. The next best statement to this effect is found at the beginning of his First Set of Replies (II:74). All others, I suggest, are implicit at best.11

At any rate, the controversy begins with the question of the independence of the second proof in the Third Meditation from the first proof. In his First Set of Replies Descartes tells us that his purpose in producing the second proof in the Third Meditation was not in fact "to produce a different proof from the preceding one, but rather to take the same proof and provide a more thorough explanation of it" (II:77). However, that the two proofs in the Third Meditation should be regarded as one proof or two does not seem later much of an issue for Descartes, as seen from his letter to Mesland dated May 2, 1644:

It does not make much difference whether my second proof, the one based on our own existence, is regarded as different from the first proof, or merely as an explanation of it. Just as it is an effect of God to have created me, so it is an effect of him to have put the idea of himself in me; and there is no effect coming from him from which one cannot prove his existence. Nevertheless, it seems to me that all these proofs based on his effects are reducible to a single one; and also that they are

11 There is another passage, found in one of Descartes' letters, which may at first seem to be as unequivocal as the previous two passages. It is in his letter to Mersenne dated July, 1641 (III:186). Here he speaks of his "main ar gument" in regard to his proofs of God's existence, and the work implied is clearly the Meditations. However, it is unclear which of the three proofs is his referent. This is especially the case if we compare this letter with the previous letter of which it is a continuant, his letter to Mersenne dated June 16, 1641 (III:183-184). Indeed at the end of this letter it may be inferred (from the comparison made to a geometric argument based on the definition of triangle; $\mathrm{cf}$. Fifth Meditation (II:46)) that the type of proof Descartes has in mind here is most properly the ontological ar gument. Hence it may be inferred that the reference to his "main ar gument" in the subsequent letter, since it is a continuation of the same problem, is the ontological argument! 
incomplete, if the effects are not evident to us ... and if we do not add to them the idea which we have of God. [III:231-232]

And yet it seems to me that, if we go back and look closely at the two proofs in the Third Meditation, although there is a close relation, there is a clear distinction, contra Descartes, between the two proofs. The first proof focuses on one particular effect, the idea I have of God, and employs an additional number of premises to prove that God exists. And though this proof also presupposes the existence of myself, my mind, at this point it is not yet thought of as an effect, and so no cause of it is yet sought. The second proof, on the other hand, does indeed begin (II:33) by considering the existence of myself, my mind, as an effect, employs (as I noted in section I) almost all of the same premises used in the first proof and adds a few new ones, and by a process of elimination arrives at the existence of God. Of course, this conclusion cannot be arrived at unless one has an idea of God to begin with. But this idea of God, as I have shown earlier, is not the conclusion of any proof, let alone the first proof, and so is free to be used in any proof.

Moreover, especially revealing in this regard is the short passage that immediately precedes the commencement of the second proof and provides the transition point between the two proofs: "I should like to go further and inquire," says Descartes, "whether I myself, who have this idea [of God], could exist if no such being [God] existed" (II:33). Notice first that the second proof is going to somehow involve the same idea of God that is used in the first proof. But more importantly, we should notice that we are being told that the second proof is going to ignore the conclusion of the first proof and is going to presuppose that God doesn't exist. Clearly the implication, then, is that the second proof is not going to be a logical continuation or extension of the first proof; and since it is not going to employ the conclusion of the first proof, it is not by further implication going to involve any of the correlates of that conclusion.

And so it would seem that the second proof is autonomous; it involves nothing that is either peculiar to the first proof or established by the first proof. 
Indeed on this issue scholarly opinion seems roughly divided. Both Norman Kemp Smith (1952:302) and Frederick Copleston (1963:111) suggest the ultimate independence though the close relation of the two proofs. Tweyman indeed provides us with a more explicit version of this view. According to Tweyman,

... at most the first proof establishes God as the cause of the idea of God and not as the cause of the conceiver of this idea. This is easily explained. For Descartes does not deal with all the features cited in the idea of God in the first proof. Descartes is certainly entitled to enumerate a variety of perfections of God as found in the idea of God, and deal with these on a selective basis, as he deems most profitable to the reader. Accordingly, if we look at the latter part of the first proof we notice that it focuses on infinitude, omniscience, etc; that is, the earlier perfections cited in the above quoted passage [II:31]. As we shall see, it is left to the second proof to develop the 'creator' aspect of God. The advantage to dealing with the attributes of God on a selective basis is dealt with in the Replies to the first set of Objections: ... [II:81-82]. [p. 171]

Failure to recognize all of this, I suggest, has led not a few scholars into confusion. Bernard Williams (1978:150-151), for instance, uncritically accepts Descartes' statement (quoted at the beginning of this section), in apparent disregard (or ignorance) of the later letter to Mesland quoted above. But more important than what Descartes elsewhere says about what he is doing in the Meditations is what he actually does in the Meditations. And from what we have seen above, what he does is apparently provide a related though ultimately autonomous argument. That that argument shares a number of premises with the first argument does not make the second argument dependent. If it did, then, had the second argument been placed first (and it clearly could have), the first argument, placed second, would have shared a number of premises 
with the second, and so by the same rationale would have to be called dependent. But this is surely specious. Williams thinks the second argument is entirely dependent on the first, and his reason for thinking this is that it shares a number of premises with the first (including the idea of God). For all of the reasons above, his argument must be rejected.

A much more challenging defense of the view that the second proof depends on the first comes from Martial Gueroult (1953). The substance of Gueroult's argument is given in the following paragraph:

Since this second proof is more absolute than the first and it can do without the principle of the correspondence of the idea with what is ideated, can it be considered as independent from the preceding one? No. It is conditioned by it, not because it assumes together with it that there must be at least as much formal reality in the cause as objective reality in my idea of the perfect, but because one of its most fundamental principles is that no faculty can be in me without my being able to have knowledge of it. This principle implies that I cannot be in myself other than what I know myself to be and that the inference from knowledge to being is valid. And this proposition is valid only if I know that God exists and cannot deceive mewhich is what the first proof demonstrates. [pp. 187-188]

This passage at first glance seems very impressive and formidable. But once we look at it again and examine it closer, we find a number of errors that make it unacceptable.

Gueroult's argument begins by telling us that one of the second proof's "most fundamental principles" is that "no faculty can be in me without my being able to have knowledge of it" (cf. II:34). This fundamental principle, moreover, this required premise, logically implies, he tells us, the implicit proposition that "I cannot be in myself other than what I know myself to be" as well as the 
more general (also implicit) proposition that "the inference from knowledge to being is valid." Now the crux of Gueroult's argument is that all of this implicitly depends on the proposition that "God exists and cannot deceive me," which, he says, "is what the first proof demonstrates."

There are a number of things wrong with this argument. First, Gueroult is crediting Descartes with a lot of implicit propositions and inferences here, propositions and inferences which might not have been originally intended by Descartes. Next, and more importantly, while it is true that the first proof demonstrates (ostensibly) God's existence, it is not true that it also demonstrates (again ostensibly) that God cannot deceive me. The conclusion that God is not a deceiver does not appear until after Descartes has finished with his second proof (II:35). The knowledge that God is not a deceiver, then, does not serve in Descartes' second proof to guarantee the truth of the proposition that "I cannot be in myself other than what I know myself to be and that the inference from knowledge to being is valid." Likewise it does not serve to guarantee the truth of the more fundamental principle that "no faculty can be in me without my being able to have knowledge of it." To think otherwise is to accuse Descartes of not following the geometric order of reasons, namely (as we saw in section I), that whatever comes before cannot be known by whatever comes later, what in his Second Set of Replies (II:110) he claimed was the program he followed in his Meditations. Certainly Gueroult would not wish to make this accusation (cf. his Preface; also p. 191). On what, then, is the truth of the principles and propositions ascribed by Gueroult to Descartes' second proof based? Interestingly, at this point it is not yet based on anything. Rather the implication is that so far they are only indubitable. (The absolute truth of clear and distinct perceptions is not concluded until after the completion of the first two proofs (II:43).) And they receive their stamp of indubitability in the exact same way as all the other premises (Scholastic or not) in the first two proofs receive it: they are intuitively clear by the natural light and therefore cannot be doubted (cf. II:27-31 and II:3334).

I suggest, then, as the sum of these reflections, that the second proof is logically autonomous. Now what of the third proof, the ontological proof in the Fifth Meditation? 
It is interesting to note once again the division among scholars on this issue. Copleston (1963:122-123), Williams (1978:153), and Mackie (1982:30), for instance, all agree that the proof in the Fifth Meditation is independent of the two proofs in the Third Meditation. On the other hand, Kemp Smith (1952) and Gueroult (1953), for instance, provide arguments for the opposite position, and since I am in disagreement with that position, and since their arguments to my mind cover all the basic possibilities, it is to their arguments that I shall now turn.

Kemp Smith's argument is rather brief and its two parts are contained in a footnote (p. 304 n.4). The first part consists of a rather curious statement: "Descartes does not, in the manner of Anselm, regard the ontological argument as an independent selfsufficient argument. Even if the idea of God be an 'essence', and as such justify certain conclusions, these conclusions can have no metaphysical validity unless and until it has been proved that the idea is divinely conditioned."

Precisely what is meant by this statement is not sufficiently spelled out by Kemp Smith. It seems most likely to me that Kemp Smith's point is that Descartes' third proof is circular in that the idea of God with which it begins presupposes that it is an effect from God, as proven in the first proof. This would seem to be why Kemp Smith proceeds to quote the following passage from the Fourth Set of Replies: "But I think it is clear to everyone that a consideration of efficient causes is the primary and principal way, if not the only way, that we have of proving the existence of God" (II:166). (I shall hereafter refer to this passage as the "primary and principal way" passage.)

A further possibility is the argument, leaving aside any matter of cause and effect, that the idea of God with which the proof in the Fifth Meditation begins is conditioned by or follows from the idea of God that we are left with at the end of the Third Meditation. In this way, then, the proof in the Fifth Meditation would depend on the two proofs in the Third Meditation. But does the text of the Meditations support this view? I suggest it does not.

One possibility is that the idea of God in the third proof is derived from the first proof in which it is concluded that God necessarily exists. But to say that God necessarily exists is not 
necessarily to say that existence is one of God's perfections. The two statements are not logically equivalent. Nor might $I$ add is the latter statement ever inferred or even so much as stated in the first proof. For Kemp Smith's argument, if his reference is indeed to the first proof, this would have to be the case. But the text does not bear him out. The fact is that the idea of God with which Descartes begins the first proof in the Third Meditation remains essentially the same throughout. Nothing is added to the idea by the end of that proof. Rather the conclusion is simply that God really exists and that his existence is without beginning or end.

A better possibility concerns the second proof. In this proof the idea of God is developed as the proof proceeds. Two new ideas are added to the original idea of God (II:34). The first is that God must be the cause of himself, the second is the inseparability of all of God's perfections. Though this inseparability is added by Descartes as a further perfection of God, it is not relevant to our discussion. The first addition, however, is very relevant. By arguing that God must be the cause of himself, Descartes is arguing in effect that God is the formal cause of himself, or in other words, that existence is part of God's essence. Indeed this is confirmed by Descartes in his Fourth Set of Replies (II:66-67), wherein he tells us that he did not make this explicit because he thought it was selfevident. In this way, then, the ontological proof in the Fifth Meditation may be thought to depend on the Third Meditation. The second proof, accordingly, not the first, might have been what Kemp Smith had in mind, and the reason for which he quoted in support the passage I quoted above from the Fourth Set of Replies.

Either way, I don't think Kemp Smith's conclusion can be maintained, as we shall see from a consideration of Descartes' writings both inside and outside the Meditations.

Interestingly, Gueroult as well (p. 243) quotes the same passage I quoted above from the Fourth Set of Replies (the "primary and principal way" passage) in order to provide textual evidence for his view that the ontological argument in the Fifth Meditation is dependent on the two proofs in the Third Meditation. But Gueroult uses it to support his own interesting interpretation of this dependence. According to Gueroult, Descartes' ontological proof in the Fifth Meditation is explicitly made analogous by Descartes 
to proofs in geometry. Now proofs in geometry (and mathematics), even though they involve clear and distinct ideas and perceptions, had their validity as well as the veracity of clear and distinct ideas and perceptions cast into doubt by the hyperbolic and metaphysical doubt of the First Meditation. This doubt was not removed, of course, until the Third Meditation, in which the existence of God was proved and it was established that he is not a deceiver (II:35), and the Fourth Meditation, in which the absolute veracity of clear and distinct ideas and perceptions was concluded from the former (II:43). The objective validity of geometric proofs, then, depends on the proof of God's existence in the Third Meditation. But since Descartes' ontological argument in the Fifth Meditation shares the same nature with geometric proofs, it too "is subject to the demonstration of the objective validity of clear and distinct ideas. And this demonstration has been supplied by the proof of God by effects" (p. 241). In other words, the proof in the Fifth Meditation "is not valid if it is isolated from it [the proofs in the Third Meditation]" (p. 248). Or yet in other words again, Gueroult's argument may be characterized as the view that the third proof depends on the acceptance of the proposition that whatever we clearly and distinctly perceive is true, that the truth of this proposition was established by Descartes as a consequence of the two proofs of God's existence in the Third Meditation, so that the ontological proof in the Fifth Meditation is not autonomous but depends on those earlier proofs of God's existence.

To all of this we may begin by contrasting two passages that would seem to contradict Kemp Smith's and Gueroult's interpretation of the dependence of the third proof. Surprisingly, these two passages fail to receive notice or even mention by either Kemp Smith or Gueroult. First, in his Synopsis to the Meditations Descartes explicitly calls his proof in the Fifth Meditation "a new argument demonstrating the existence of God" (II:11). But I will admit that, though indeed highly suggestive, one cannot logically deduce from these words that the "new argument" is unrelated, let alone self-sufficient. A related and dependent argument may without contradiction be properly called a "new" argument; what may warrant the qualifier "new" may be elements in the argument not found in the original argument. 
Replies:

But now consider the following passage from the First Set of

... as I readily admit, it [the ontological argument in the Fifth Meditation] is the kind of argument which may easily be regarded as a sophism by those who do not keep in mind all the elements which make up the proof. For this reason I did have considerable doubts to begin with about whether I should use it; for I feared it might induce those who did not grasp it to have doubts about the rest of my reasoning. But there are only two ways of proving the existence of God, one by means of his effects, and the other by means of his nature or essence; and since I expounded the first method to the best of my ability in the Third Meditation, I thought that I should include the second method later on. [II:85; italics mine.]

There are four things that should be noticed from this passage. First, that Descartes seems clearly to assert that there are basically two different types or ways of proving God's existence, neither one dependent on the other, each as logically valid as the other. Second, that though both types are equally valid logically, the first type (from effects) is psychologically more powerful and therefore more likely to convince the reader than the latter type (from essence). Third, that this is why Descartes placed the ontological argument last: he was afraid that if he placed it earlier in the Meditations (and he clearly implies that he could have), then what follows in the Meditations would have been less likely to be accepted. Fourth, and most important for the matter in hand, that Descartes' ontological argument does not proceed in any way from an effect. 12

12 In support of this, see the Conversation with Burman, in which Descartes is reported to have explicitly stated that his ontological proof in the Fifth Meditation "does not start from some ef fect" (III:337). 
Of course, this approach of citing passages against each other can prove nothing except at most a particular contradiction in Descartes' writings. But I will suggest that there is not even a contradiction here, and that both Kemp Smith and Gueroult have misread the "primary and principal way" passage, much to the detriment of their respective interpretations of the ontological proof in the Fifth Meditation. The "primary and principal way" passage, it will be recalled, refers to proving the existence of God by efficient causes. The two proofs in the Third Meditation, of course, are quite clearly proofs from efficient causes. The proof in the Fifth Meditation, on the other hand, appears to be not so at all. In it there is no mention of causality whatsoever. Kemp Smith, therefore, includes in the referent of the "primary and principle way" of proving God's existence the ontological argument, but suggests its inclusion is because that proof is conditioned by and depends on the first two proofs. Gueroult, on the other hand, also thinks the third proof depends on the first two, but then concludes, since the third proof is not a proof from an efficient cause, that it is excluded from the referent in the "primary and principal way" passage. Both of these interpretations, I suggest, are wrong, and not so much because of the two passages I quoted above that contradict them, but because they have misinterpreted both the nature of Descartes' ontological argument and the "primary and principal way" passage.

That they have misinterpreted the "primary and principal way" passage is, I think, borne out by a close examination of its context. But first, let us quote once again the "primary and principal way" passage, this time, however, including its immediate context:

But I think it is clear to everyone that a consideration of efficient causes is the primary and principal way, if not the only way, that we have of proving the existence of God. We cannot develop this proof with precision unless we grant our minds the freedom to inquire into the efficient causes of all things, even God himself. ... In every case, then, we must ask whether a thing derives its existence from itself or from something else; and by this 
means the existence of God can be inferred, ... [II:166]

The context of this passage, it should be noted, is the question whether God can be the cause of himself. In the Fourth Set of Objections (II:147-148) Arnauld raised this difficulty and concluded in the negative. Descartes' reply is found in the context containing the passage quoted above. But if we look at this passage carefully, and what immediately follows it, we will notice that the reference is not only to the argument about God being the cause of himself, but also to arguments that prove the existence of God from effect to cause. Just below the passage quoted above Descartes makes a distinction between efficient and formal causality: something which derives its existence from something else does so by an efficient cause, while something which derives its existence from itself does so by a formal cause. That the conclusion of the Third Meditation is that the existence of the idea of God in my mind as well as the existence of myself could not have proceeded from any cause but God is clear. The two proofs in the Third Meditation, therefore, are clearly proofs involving what Descartes calls an efficient cause. Now what does Descartes say in the passage quoted above about this type of proof? He says quite clearly that it is "the primary and principal way, if not the only way, that we have of proving the existence of God." From this one might naturally infer that the third proof, the ontological proof in the Fifth Meditation, since it apparently does not involve efficient causality, is either excluded from this "primary and principal way" or is included but merely as a tag-along because of its dependence on the first two proofs.

But this is to either completely misunderstand or totally ignore the meaning of the context of this passage. Descartes' point is that in God being the cause of himself, both God as formal cause of himself and God as efficient cause of himself coalesce. (This is hinted at even in the immediate context of the passage as I quoted it above.) "Those who follow the sole guidance of the natural light," he goes on to say, "will in this context spontaneously form a concept of cause that is common to both an efficient and formal cause: ..". (II:166). The ontological argument, being an argument from a formal cause, from essence, is therefore quite apparently included 
in the category "efficient cause" in the "primary and principal way" passage. In this light, then, not only are both Kemp Smith and Gueroult shown to be wrong in their respective interpretations of the "primary and principal way" passage, but they lose one of their prime pieces of textual support. Moreover, Descartes is saved from a contradiction with the two passages I quoted in contrast, particularly the "two ways of proving the existence of God" passage from the First Set of Replies.

It is of course true that Descartes goes on in this "primary and principal way" section to further qualify what he means and he ends up by saying that God is not literally the efficient cause of himself. Rather "the formal cause will be strongly analogous to an efficient cause, and hence can be called something close to an efficient cause" (II:170). But this does not detract from my point and add anything in either Kemp Smith's or Gueroult's favor. For whether taken literally or analogously, Descartes' ontological argument is still included in the category "efficient cause" in his "primary and principal way" passage.

Moreover in this very passage it will be noticed that Descartes does not say that the "primary and principal way" proofs must involve efficient causality (as Kemp Smith and Gueroult would have us believe); rather he says only that they must involve a consideration (his own word) of efficient causes. This makes quite a difference. For now the consideration of efficient causes need not even concern itself specifically with (let alone depend on) the question of the efficient cause of my idea of God or the efficient cause of myself (the two questions in the Third Meditation). It need only ask what would be the efficient cause of God if God exists. Descartes' concluding point is that unless one is able to ask for the efficient cause of everything, including God, one will never be able to arrive at the conclusion of God as formal cause of himself. And his analogy for this is Archimedes' proof in which the properties of a sphere are demonstrated from taking a cube and increasing its number of sides to infinity. If one denies beforehand that a sphere can in any sense be a rectilinear figure, "in saying this he would not only be failing to establish Archimedes' result, but would be preventing himself and others from properly understanding the proof' (II:171). 
But the proof is in the pudding, as the saying goes, and to best establish the independence of Descartes' ontological argument we must return to the Meditations and examine the way in which that proof is given.

There is a passage early in the Fifth Meditation in which any link with the previous Meditations is severed. Descartes says "even if it turned out that not everything on which I have meditated in these past days is true, I ought still to regard the existence of God as having at least the same level of certainty as I have hitherto attributed to the truths of mathematics" (II:45). Why? Two reasons. First, because, as he says right above this passage, "the idea of God, or a supremely perfect being, is one which I find within me just as surely as the idea of any shape or number." And second, because his ontological proof is basically akin to proofs in mathematics and geometry (cf. II:47). In severing any link to the previous Meditations, we may therefore infer that the ontological argument in the Fifth Meditation does not presuppose the metaphysical and hyperbolic doubt of the First Meditation, nor the proofs in the Third Meditation or their consequences. Indeed these may even be rejected! (The Cogito, of course, remains, but it is without relevance.) The third proof presupposes a quite different approach. Its design is apparently to command the assent that God really exists of those who, whether theistic or atheistic, consider the proofs of geometry and mathematics indubitable and true. His point is that if you find the latter type of proofs convincing, then you are logically compelled to accept his ontological proof. There is no question of absolute certainty here; what is asserted is only at least a comparable degree of certainty. We may therefore infer that there is nothing in this that presupposes anything from the previous Meditations. There is no reason, therefore, why Descartes' ontological argument cannot by itself be valid. 13

13 Interestingly, in both the First and Second Set of Replies Descartes recasts his ontological argument into a clear syllogistic form, complete with a major premise. a minor premise, and a conclusion. The two versions, however, are not exactly identical. In the version given in the First Set of Replies (II:83), the clear and distinct is fully explicit in both premises. In the version given in the Second Set of Replies (II:106-107), on the other hand, the clear and distinct is semj-explicit in the major premise and missing altogether in the minor premise. In spite of these 
Gueroult, of course, as we have seen, denies this. But not only may we reject his reasons for this, as I think I have shown, but we should also notice that he confuses soundness with validity. Gueroult thinks Descartes' ontological argument cannot by itself be valid because it presupposes the veracity of clear and distinct ideas and this was established by the two proofs from effects. But even if Gueroult is right about this dependence, this would at best only establish that Descartes' ontological argument cannot by itself be justifiably sound. His ontological argument can still be justifiably valid. It is a simple point of logic that for an argument to be valid its premises do not have to be true but only supposed to be true.A valid argument is after all a conditional argument. A sound argument, on the other hand, requires true premises in addition to validity.

But more importantly what Gueroult fails to appreciate is that in a sense all three proofs are on a par. If the third proof requires for its soundness true premises, and if these can only be guaranteed by establishing the veracity of clear and distinct ideas, then the same is the case with the first two proofs. The veracity of their premises cannot be guaranteed by God without involving a vicious circle. Instead Descartes tentatively guarantees their veracity by consequence of the Cogito (II:24). Gueroult (p. 243) thinks this is good enough to make the proofs sound, but he is wrong. This guarantee from the Cogito is not an absolute guarantee. That can only follow from the existence of God. The two proofs in the Third Meditation, therefore, just like the proof in the Fifth Meditation,

differences the point to notice is that in both cases Descartes clearly thought each version valid on its own (contra Gueroult, p. 249) and without recourse to the two proofs from effects. The version in the First Set of Replies, however, may seem at first to contradict this interpretation, for Descartes therein tells us that "the major premise cannot be denied, because it has already been conceded that whatever we clearly and distinctly understand is true." This at first may seem an explicit confirmation of Gueroult's interpretation (though Gueroult wisely does not use it). that the third proof depends on the first two proofs because the first two proofs establish the veracity of clear and distinct ideas and perceptions. But contrary to appearances, this First Reply does not support Gueroult's view. In what I just quoted. Descartes' reference is not to the two proofs from ef fects, or to their consequences; instead, his reference is simply to Caterus' acceptance (cf. II:81 and II:69) of the veracity of clear and distinct ideas and perceptions. 
can at best be regarded only as valid; to regard any of them as sound cannot be done without vicious circularity. 14

We may also note in this regard that at the end of the Fifth Meditation (II:48) Descartes seems to conclude from his ontological proof, just like he did following his two earlier proofs (II:43), the veracity of clear and distinct ideas. This further suggests the independence of the third proof.15

Finally, we may briefly note the fact that in both the Principles of Philosophy and the Second Set of Replies the ontological proof

14 In reply to the charge of circularity, Descartes in his Second Set of Replies answers that "as soon as we think that we correctly perceive something, we are spontaneously convinced that it is true" (II:103) and that some clear and distinct perceptions of the intellect "are so transparently clear and at the same time so simple that we cannot ever think of them without believing them to be true" (II:104). Descartes gives two examples, the Cogito and the proposition that "what is [once] done cannot be undone." He tells us furthermore that our faculty of clear and distinct perception is the highest faculty we have. that its judgments "could not be corrected by any clearer judgments or by means of any other natural faculty" (II:103). But even if we grant Descartes' claims about this psychological necessity, that there are some propositions that while thought of cannot possibly be doubted, and even if we grant further that in cases such as the Cogito this psychological necessity entails an epistemological necessity , it by no means follows that for all cases this psychological necessity by itself entails an epistemological necessity. In other words. just because we are psychologically incapable of doubting something does not by itself guarantee that that something is true. Indeed Descartes seems to admit as much when he says "we have everything that we could reasonably want. What is it to us that someone may make out that the perception whose truth we are so firmly convinced of may appear false to God or an angel, so that it is, absolutely speaking, false? Why should this alleged 'absolute falsity' bother us. since we neither believe in it nor have even the smallest suspicion of it?" (II:103). The reason it should bother us. I should think, is because if while attending to each and every one of the premises that Descartes provides in his three proofs of God' s existence it is nevertheless possible that they could be false. in spite of our finding them clear and distinct and therefore psychologically indubitable (which itself is dubitable, see note 5 above), then those proofs fail from an epistemological point of view and can only be made sound by presupposing what is in dispute, namely the existence of God. Hence the circular ity difficulty remains.

15 In contrast it is interesting to note that in the Principles of Philosophy (I:203) Descartes establishes the veracity of clear and distinct ideas and perceptions only well after he has given his three proofs of God's existence. Even more curious (and paradoxical) is that in his Second Set of Replies (II:1 16) the veracity of clear and distinct ideas and perceptions is presupposed before the three proofs are given. 
is given first and the other two proofs follow after. This further suggests that Descartes thought his ontological proof independent of the other two proofs.

Incidentally, Gueroult (p. 257) attempts to obviate this problem by arguing that in these two works the synthetic style is employed in which the order of topics is followed rather than the order of discovery or reasons. This, says Gueroult, allows Descartes to provide his ontological proof first even though it depends on the two proofs which come after it. But then we may ask why Descartes did not put this proof third as he did in the Meditations. To this Gueroult gives no satisfying reply. But most importantly Gueroult has misunderstood what Descartes says in the Second Set of Replies about the analytic and synthetic styles of demonstration-his quotation from Burman (III:337-338) notwithstanding. According to Descartes both styles employ the geometric order, in which (as I mentioned in section I) "the items which are put forward first must be known entirely without the aid of what comes later" (II:110). If, as Gueroult claims, Descartes' ontological proof depends on the two proofs from effects, we must then conclude that in the Second Set of Replies and in the Principles Descartes erred by forgetting to follow the proper order. But all things considered, the error would seem to be Gueroult's.

\section{III}

Finally, if it is correct to think that all three proofs of God's existence in the Meditations are logically autonomous, why then do we find them in the order in which they are given there? If there are no logical or methodological reasons, is the result the product of chance or whim? Or perhaps they are given autobiographically in the order in which Descartes originally discovered or conceived them. And then perhaps their ordering is principally for psychological reasons.

I suggest Descartes himself gives us the answer to these questions, and that his fundamental consideration was not an "order of the reasoning," strictly so called, as he sometimes implies (cf. II:110 and III:163), nor simply the order in which Descartes "discovered" the proofs, as Burman naively quotes him as saying 
(III:337), but instead psychological considerations, namely persuasion and acceptance. In his Second Set of Replies Descartes tells us that there may be some readers "whose natural light is so meagre that they do not see that it is a primary notion that every perfection that is present objectively in an idea must really exist in some cause of the idea" (II:97-98). For the benefit of these unfortunates, he then proceeds to tell us, "he provided an even more straightforward demonstration [his second proof] of God's existence." The import of this passage, then, seems plain enough: if the reader isn't bright enough to be convinced by the first proof, he may still be bright enough to be convinced by the second proof. Nevertheless, Descartes believed that it is only the educated few who will ever be able to grasp his arguments (cf. II:5 and II:172), and then many or even most of them may never be able to (cf. III:198).

Now what about the third proof, the ontological argument in the Fifth Meditation? That this argument is found two Meditations later and not in the Third Meditation with the others, is, as I hope I have already shown, not for any logically or methodologically necessary reasons. Why it is left so late, it turns out, is once again because of considerations of persuasion and acceptance. Just as Descartes thought that many would be unconvinced by the first proof because of their inability to grasp a particular principle, so he thinks the case is even more so with the third proof. The problem now, however, is not the lack of brightness on the part of the many readers to grasp a particular principle; rather it is what Descartes considers to be an even greater problem, the inability to break a particular habit of mind. This clearly comes out in his First Set of Replies wherein Descartes notes what he calls a "considerable difficulty." The difficulty is that "we are so accustomed to distinguishing existence from essence in the case of all other things that we fail to notice how closely existence belongs to essence in the case of God as compared with that of other things" (II:83). Indeed so great is this habit of mind of always separating existence from essence that Descartes expressed "considerable doubts" (II:85) about whether he should even use the ontological argument. He feared that if he used it earlier on (presumably with the other two proofs in the Third Meditation), "it might induce those who did not 
grasp it to have doubts about the rest of my reasoning" (II:85). He therefore opted to place the ontological proof later on, presumably where it would do the least damage if unsuccessfully grasped.Also, by placing it "later on," the mind of the reader might be more pliant and more disposed to breaking previous habits, as a result of having undergone more meditations, than it would be earlier on, so that it might be more ready to accept the argument at a later point (in the Fifth Meditation) than at an earlier point (in the Third Meditation).

Finally, I should like to point out as further evidence the fact already mentioned that the three proofs in the Meditations appear in a different order in two other places. In both the Principles of Philosophy and the Second Set of Replies the third argument appears first, followed by the first and second arguments respectively. The purpose of the Principles, Descartes tells us in his letter to Mersenne dated December 31,1641 , is to present his philosophy "in an order which will make it easy to teach" (III:167). A principal difference between it and the Meditations, he further tells us, is that what is explained in detail in one is explained briefly in the other, and vice versa. In the Second Set of Replies (II:110-120) Descartes' purpose is not altogether unrelated. He agrees to state the overall argument of the Meditations in a compact form, in what for him is the geometric synthetic style. This style employs definitions, postulates, axioms, propositions and demonstrations. Descartes does not prefer this style, however, even though he says it is more compelling to the stubborn and argumentative reader. He prefers what for him is the geometric analytic style, which is the style he used in the Meditations. This style is more engaging to the mind, he claims, since, though it is longer and more involved, it proceeds methodically in the order in which the material was discovered and so makes the reader feel that he is discovering the arguments for himself.

And so, as a final remark, if we combine this information about the analytic and synthetic styles with what we discovered earlier about what Descartes says about the respective psychological degrees of difficulty of the three proofs, then a most interesting modus operandi emerges. When Descartes wants to engage the mind of the reader in a sort of intellectual adventure or process of discovery, we get what we find in the Meditations (also the 
Discourse on Method (I:128-129)). Here the psychologically intermediate proof (the first proof in the Third Meditation) comes first, the psychologically easiest proof (the second proof in the Third Meditation) follows immediately after it, and the psychologically most difficult proof (the ontological proof in the Fifth Meditation) comes third and later on. On the other hand, when Descartes wants to present his philosophy in a dry and systematic fashion, we get what we find in his textbook, the Principles of Philosophy, and in his proofs in the synthetic style of the existence of God in his Second Set of Replies. Here, quite interestingly (and I don't think accidentally), in both works the psychologically most difficult proof (the ontological proof in the Fifth Meditation) comes first, the psychologically intermediate proof (the first proof in the Third Meditation) comes second, and the psychologically easiest proof (the second proof in the Third Meditation) comes third.

I suggest that essentially prudential concerns are at work here. When faced with opponents, a wise strategy might be, if you have three forces ranked in degrees of strength, to engage the enemy first with your weakest force, follow that with your intermediate force, and then, now that the enemy is worn down, finish them off with your strongest force. This strategy would correspond to Descartes' ordering of the three proofs in the Principles and the Second Set of Replies, both of which are expressly intended for convincing stubborn and argumentative readers.

On the other hand, when dealing not with an enemy but now eager and willing students and friends, a prudent approach would be to leave your most difficult proof for last and later on in your teaching/training program, so as not to discourage your disciples early on and ruin their confidence and impede their progress. In line with this thinking it might be prudent to present them with the intermediately difficult proof first followed immediately by the easiest proof. All of this, I suggest, might well be viewed as maximally conducive psychologically to the process of intellectual adventure and discovery and development in eager and willing minds, and is the order of proofs we find in the Meditations.

This is all hypothesis, of course, and there is no textual evidence in Descartes' corpus to support it directly. Nevertheless, given the evidence and conclusions of the first two sections of this paper, in 
the absence of logical and methodological ties between Descartes' three proofs of God's existence the search for psychological considerations in his ordering of the three proofs is altogether appropriate and the above hypothesis not at all unlikely. 16

16 I am indebted to Professor Georges Moyal of Glendon College, York University. Toronto, and to two anonymous referees of Auslegung for their helpful comments and criticisms. Any misunderstandings of Descartes' philosophy that have remained are entirely my own. 


\section{References:}

Clarke, Desmond M. (1977). “Descartes' Use of 'Demonstration' and 'Deduction'." The Modern Schoolman (54:333-344). Reprinted in Stanley Tweyman, ed. (1993:105-117). René Descartes: Meditations on First Philosophy in Focus. London: Routledge.

Copleston, Frederick C. (1955). Aquinas. Harmondsworth: Penguin Books.

- - (1963). A History of Philosophy. Volume 4. Garden City: Image Books.

Cottingham, John, et al., eds. (1985, 1991). The Philosophical Writings of Descartes. Three Volumes. Cambridge: Cambridge University Press.

Frankfurt, Harry G. (1966). “Descartes' Discussion of His Existence in the Second Meditation." The Philosophical Review (75:329356).

Gueroult, Martial (1953). Descartes selon l'ordre des raisons. Paris: Aubier-Montaigne. Roger Ariew, trans. (1984). Descartes. Philosophy Interpreted According to the Order of Reasons. Minneapolis: University of Minnesota Press.

Hatfield, Gary (1986). "The Senses and the Fleshless Eye: The Meditations as Cognitive Exercises." In Rorty (1986:45-79). Hintikka, Jaakko (1962). "Cogito, Ergo Sum: Inference or

Performance?" The Philosophical Review (71:3-32).

- - (1963). "Cogito, Ergo Sum as an Inference and a

Performance.” The Philosophical Review (72:487-496).

Jolley, Nicholas (1992). "The Reception of Descartes'Philosophy."

In John Cottingham, ed. (1992:393-423). The Cambridge

Companion to Descartes. Cambridge: Cambridge University Press.

Kemp Smith, Norman (1952). New Studies in the Philosophy of

Descartes. New York: St. Martin's Press Inc.

Loeb, Louis E. (1986). "Is There Radical Dissimulation in

Descartes' Meditations?" In Rorty (1986:243-270).

Mackie, J.L. (1982). The Miracle of Theism. Oxford: Oxford University Press. 
Rorty, Amélie Oksenberg, ed. (1986) Essays on Descartes' Meditations. Berkeley: University of California Press.

Tweyman, Stanley (1979). “Deus ex Cartesio." Studia Cartesiana. Amsterdam: Quadratures (1:167-181).

Williams, Bernard (1978). Descartes: The Project of Pure Enquiry. Harmondsworth: Penguin Books. 